\title{
Diagnosis of infections with Shiga-like toxin-producing Escherichia coli by use of enzyme-linked immunosorbent assays for Shiga-like toxins on cultured stool samples
}

\author{
D. LAW, A. A. HAMOUR $\dagger$, D. W. K. ACHESON $\ddagger$, H. PANIGRAHI§, LEELA A. GANGULI \\ and D. W. DENNING*†
}

Department of Microbiology and * Department of Medicine, Hope Hospital, Eccles Old Road, Salford M6 8HD, † University of Manchester, Regional Department of Infectious Diseases and Tropical Medicine, Monsall Hospital, Newton Heath, Manchester M10 8WR, $₫$ Department of Medicine, Division of Geographic Medicine and Infectious Diseases, 750 Washington Street, NEMCH\#41, Boston, MA, USA and § Department of Microbiology, Monsall and North Manchester General Hospitals, Manchester M8 6RB

\begin{abstract}
Summary. Shiga-like toxin-producing (SLT) Escherichia coli, particularly those belonging to serogroup O157, are responsible for haemorrhagic colitis, haemolytic uraemic syndrome and some cases of gastro-enteritis. The rapid and reliable diagnosis of all these infections is necessary for correct patient management and for epidemiological reasons, but is rarely possible with present methods. We compared the efficacy of two methods, (i) the culture of faeces in broth that contained mitomycin $\mathrm{C}$ followed by enzyme-linked immunosorbent assay (ELISA) for SLTs, and (ii) the culture of faeces on sorbitol MacConkey agar (SMA), in the detection of infections caused by SLT-producing E. coli. SLT-producing E. coli O157 strains were isolated on SMA from 42 of 475 faecal samples, but SLTs were detected by ELISA in culture supernates or lysates of 54 of 475 samples. SLT-producing E. coli strains were isolated subsequently from 11 of 12 ELISA-positive, SMA culture-negative samples by a colony blot technique. In four cases, SLT-producing E. coli of serogroups other than O157 were isolated and in seven cases E. coli $\mathrm{O} 157$ was isolated in small numbers. The ELISA is a rapid and sensitive technique for the diagnosis of SLT-producing $E$. coli infection, especially where low numbers of the organism are present in faeces and when the infection is caused by a serogroup other than $\mathrm{O} 157$.
\end{abstract}

\section{Introduction}

Human infections associated with strains of Escherichia coli that produce Shiga-like toxin (SLT) or verotoxin present as non-bloody diarrhoea, bloody diarrhoea or haemorrhagic colitis (HC).$^{1,2}$ Haemolytic uraemic syndrome (HUS) and thrombotic thrombocytopaenic purpura are also associated with infection with SLT-producing E. coli. ${ }^{1,3,4}$ Although one serotype, O157:H7, predominates in most human infections with SLT-producing $E$. coli, infections can be caused by at least $30 \mathrm{O}$ serogroups of E. coli. ${ }^{4}$ The true incidence of SLT-producing $E$. coli infection is probably underestimated because of the limitations of the currently available diagnostic tests. The culture on sorbitol MacConkey agar (SMA) as used by many laboratories only detects $E$. coli strains of serogroup O157 that do not ferment sorbitol, whereas most other $E$. coli serotypes ferment sorbitol. ${ }^{5}$ Moreover, the numbers of SLT-producing $E$. coli in the faeces of patients with HC and HUS decreases markedly as the

Received 26 April 1993; revised version accepted 1 Oct. 1993. diseases progress and this reduces the probability of isolating the infecting organism later in the diseases. ${ }^{6}$

Shiga-like toxins can be detected in faeces and from cultures of $E$. coli with cytotoxicity assays ${ }^{5,7}$ and toxinneutralising antibodies are required to ensure specificity. DNA probes that hybridise with SLT-I or SLT-II have been developed ${ }^{8}$ and have proved useful in clinical studies. ${ }^{9-11}$ The polymerase chain reaction (PCR) has also been applied to the detection of SLTproducing E. coli in clinical samples. ${ }^{12}$ At present these techniques are not widely available in routine clinical microbiology laboratories.

Immunological techniques for detecting SLTs, such as enzyme-linked immunosorbent assays (ELISA), have been described. ${ }^{13,14}$ Recently, we developed a diagnostic system based on the culture of faecal samples in broth containing mitomycin $\mathrm{C}$, followed by ELISA for SLT-I and -II. ${ }^{15}$ This assay is based on the principle that the toxins produced in most human SLT-producing $E$. coli infections are mediated by bacteriophage and are, therefore, inducible with mitomycin $\mathrm{C}^{16}$ This method amplified toxin production and allowed detection of low numbers $(<1$ in 1000) of 
SLT-II-producing organisms in spiked faecal samples. ${ }^{15}$ Because the method detects toxins it is independent of serotype and can also detect infection by serogroups other than O157.

In the present study, standard detection methods for SLT-producing $E$. coli by culture on SMA were compared directly with the ELISA assay in a prospective study, and the results were correlated with the clinical presentation of patients with diarrhoea.

\section{Materials and methods}

\section{Clinical definitions}

The diagnosis of HUS was made on clinical grounds on the basis of acute renal impairment and microangiopathic anaemia. $\mathrm{HC}$ was defined as severe bloody diarrhoea with very little stool content, abdominal pain and little or no fever. Bloody diarrhoea was defined as the passage of frequent bloody stools.

\section{Samples}

Samples of faeces were obtained from patients admitted to Hope Hospital, Salford, from the community around the hospital and from patients admitted to the Regional Department of Infectious Diseases and Tropical Medicine at Monsall Hospital, Manchester. Therefore, these samples were from relatively unselected cases of diarrhoea although they tended to have more severe illness. In the latter part of the study, samples were received from other laboratories in the Region, usually when conventional cultures for enteric pathogens were negative or when $E$. coli $\mathrm{O} 157$ had been isolated, for confirmation of toxin production by the isolate. After receipt, samples were stored at $4^{\circ} \mathrm{C}$ before testing.

Faecal samples were allocated to one of four patient groups based upon clinical criteria: group 1 comprised patients with HUS; group 2, patients with HC; group 3 , patients with a history of bloody diarrhoea and group 4, patients with non-bloody diarrhoea.

\section{Bacteriological procedures}

Samples were examined for bacterial, viral and protozoal pathogens by protocols in place at the referring laboratory. Faecal samples for SLT-producing $E$. coli examination were inoculated on to Sorbitol MacConkey Agar No. 3 plates (SMA; Unipath) which were examined for the presence of sorbitol non-fermenting (SNF) colonies. Slide agglutination tests on SNF colonies were performed with $E$. coli O157 antiserum (Difco). Organisms that reacted with the antiserum were then tested for toxin production as described below. When SNF colonies were scanty or several colonial types of SNF were observed, each type was inoculated on to SMA and agglutination tests were repeated after overnight incubation. Isolates that reacted with $E$. coli $\mathrm{O} 157$ antiserum were then ident- ified by the API 20E system (bioMérieux, Basingstoke).

\section{Culture conditions}

For ELISA, c. $0 \cdot 1 \mathrm{~g}$ of faeces were emulsified in $3 \mathrm{ml}$ of sterile phosphate-buffered saline (PBS), $\mathrm{pH} 7.4$ and $30 \mu \mathrm{l}$ of the suspension were used to inoculate $3 \mathrm{ml}$ of Tryptone Soy Broth (TSB; Difco) containing mitomycin C (TSB + mit C; Sigma) $200 \mathrm{ng} / \mathrm{ml}$. Broths were incubated for $18 \mathrm{~h}$ at $37^{\circ} \mathrm{C}$ with constant shaking $(200 \mathrm{rpm})$. Cultures were centrifuged and the supernates were used for SLT-II testing. The cell pellet was resuspended in $300 \mu \mathrm{l}$ of polymyxin B (Sigma) $2 \mathrm{mg} /$ $\mathrm{ml}$ in PBS, incubated at $37^{\circ} \mathrm{C}$ for $10 \mathrm{~min}$ and then centrifuged. The clear supernate was removed and used to test for SLT-I.

\section{ELISA procedure}

The ELISA was performed as described previously ${ }^{15}$ hydatid cyst material was used to capture toxin. Rabbit anti-SLTI and anti-SLTII, prepared as described previously, ${ }^{13}$ and goat anti-rabbit alkaline phosphatase conjugate were used to detect bound toxin. After 100 samples had been processed in this way, the assay for SLT-II was modified in that a monoclonal antibody (MAb), 2B1, specific for SLT-II B subunit, ${ }^{16}$ was used to capture this toxin instead of hydatid cyst material, because this technique was shown to be more sensitive. Mouse ascitic fluid ( $3 \mu$ in $10 \mathrm{ml}$ of PBS) was used to coat the assay plate. To quantify the amount of toxin in the supernates and lysates, Shiga toxin and SLT-II, purified as described previously ${ }^{17}$ and diluted in PBS (range 1.6-100 ng/ml) were used as standards in the ELISA. The positive/ negative cut-off point for both toxins in culture preparations was $1.6 \mathrm{ng} / \mathrm{ml}$. As a control, E. coli O157:H7 (strain 933 provided by the late Dr H. Williams-Smith) which produces SLT-I and II, was inoculated into TSB + mit $C$ and processed at the same time as the cultures.

The ability of E. coli colonies to produce SLTs was tested after growth in TSB + mit C. Supernates and cell lysates were prepared and tested as described above. When a sample was ELISA-positive, but SMAnegative, sweeps of colonies were inoculated into TSB + mit C, incubated as described above, and cell lysates and supernates were tested by ELISA. If these preparations gave positive results individual colonies were then tested for their ability to produce toxin.

\section{Colony blot technique}

Colony blots were performed on 12 ELISA-positive samples which gave negative results on SMA culture, and on 14 samples from patients with HUS which gave negative results by both ELISA and SMA culture. Tryptone soy agar (TSA) containing mitomycin C $200 \mathrm{ng} / \mathrm{ml}$ was prepared. Two $0 \cdot 45-\mu \mathrm{m}$ nitrocellulose filters (BioRad, Hemel Hempstead) were placed on top 
Table. Results of investigations for Shiga-like toxin-producing E. coli on 475 faecal samples

\begin{tabular}{|c|c|c|c|c|c|c|c|}
\hline \multirow{2}{*}{ Diagnosis } & \multirow{2}{*}{$\begin{array}{l}\text { Number of } \\
\text { samples }\end{array}$} & \multicolumn{3}{|c|}{ Toxin detected by ELISA } & \multirow{2}{*}{$\begin{array}{l}\text { E. coli O157 } \\
\text { isolated } \\
\text { on SMA }\end{array}$} & \multirow{2}{*}{$\begin{array}{l}\text { SLT-producing } \\
\text { E. coli isolated } \\
\text { colony blot }\end{array}$} & \multirow{2}{*}{$\begin{array}{l}\text { Number of ELISA- } \\
\text { positive, SMA culture } \\
\text { negative samples }\end{array}$} \\
\hline & & SLT-I & SLT-II & SLT-I and II & & & \\
\hline $\mathrm{HC}$ & 10 & 0 & 10 & 0 & 8 & 2 & 0 \\
\hline HUS & 25 & 0 & 11 & 0 & 8 & 3 & 0 \\
\hline $\begin{array}{l}\text { Bloody } \\
\text { diarrhoea }\end{array}$ & 320 & 2 & 18 & 8 & 23 & $4^{*}$ & 1 \\
\hline $\begin{array}{l}\text { Non-bloody } \\
\text { diarrhoea }\end{array}$ & 120 & 0 & 4 & 1 & 3 & 2 & 0 \\
\hline Total & 475 & 2 & 43 & 9 & 42 & 11 & 1 \\
\hline
\end{tabular}

HC, haemorrhagic colitis, HUS, haemolytic uraemic syndrome.

* All four isolates belonged to non-O157 serogroups.

of each other on a TSA plate and $25 \mu \mathrm{l}$ of faecal suspension $(0.5 \mathrm{~g}$ in $10 \mathrm{ml}$ of PBS) was spread over the surface of the upper filter. The plate was then incubated at $37^{\circ} \mathrm{C}$ for $18 \mathrm{~h}$ which resulted in c. 200 $1000 \mathrm{cfu} /$ plate. The lower filter was removed and then blocked with bovine serum albumin $1 \%$ in PBS for $1 \mathrm{~h}$ at $22^{\circ} \mathrm{C}$. The filter was then probed with rabbit antitoxin to SLT-I and -II diluted 1 in 6000 in PBS for $1 \mathrm{~h}$ at $22^{\circ} \mathrm{C}$. After washing in PBS-Tween $200.05 \%$ the filters were exposed to goat anti-rabbit IgG phosphatase conjugate diluted 1 in 6000 in PBS for $30 \mathrm{~min}$ at $22^{\circ} \mathrm{C}$. After washing in PBS-Tween 20, the filter was finally developed with nitroblue tetrazoliumbromo-chloroindoxyl phosphate (BioRad). The presence of purple areas on the filter indicated potential toxin-producing colonies. The filter was then aligned with the top filter and blot-positive colonies were picked off the top filter, subcultured for purity, and tested for toxin production by ELISA. As a control for colony blots a mixture of $E$. coli O157: $\mathrm{H} 7$ (strain 933) with $E$. coli $\mathrm{C} 600$ was processed as if it were a faecal suspension.

The toxigenic potential of $\mathrm{O} 157$ and non-O157 isolates was confirmed by the Division of Enteric Pathogens, Central Public Health Laboratory, London.

\section{Results}

\section{Correlation of ELISA with SMA culture}

A total of 475 faecal samples from 457 patients was examined in this study. E. coli $\mathrm{O} 157$ strains were isolated by SMA culture from 42 samples. However, 54 samples gave positive ELISA results (43 SLT-II only, nine SLT-I and -II and two SLT-I only; table). Therefore, the ELISA detected 12 apparent SLTproducing $E$. coli infections that were not detected by SMA culture. SLT-producing $E$. coli were subsequently detected in 11 of 12 ELISA-positive, SMA culture-negative samples by the colony blot technique and by testing colony sweeps. In seven instances, low numbers of $E$. coli $\mathrm{O} 157$ were isolated and in four instances SLT-producing $E$. coli of serogroups other than $\mathrm{O} 157$ were isolated (two serogroup O128, one serogroup O103, the one other untyped). E. coli colonies from the remaining ELISA-positive, SMAnegative sample gave negative results by colony blot.

In each case of SLT-producing $E$. coli infection in this study, the organism was isolated as the sole recognised pathogen. Thirty-six samples yielded a pathogen other than an SLT-producing $E$. coli and in none of these cases was the SMA culture positive for $E$. coli $\mathrm{O} 157$ or the ELISA positive for SLT-I or -II.

\section{Clinical correlation}

All of 10 faecal samples from cases of $\mathrm{HC}$, were ELISA-positive for SLT-II after culture, but only eight yielded E. coli $\mathrm{O} 157$ on SMA. The remaining two samples gave positive results for $E$. coli 0157 on colony blot but the organisms were present in very low numbers and were likely to have been overgrown by non-O157 serogroups on SMA. Twenty-five faecal samples were examined from 19 patients with clinically typical HUS. Eleven ( $44 \%$ ) samples from nine patients were ELISA-positive but only eight $(32 \%)$ of these samples yielded $E$. coli 0157 directly on SMA. The remaining three samples yielded SLT-II-producing $E$. coli isolates on colony blot which were shown subsequently to be serogroup O157. Fourteen samples from HUS patients, most of which were obtained late in the illness, gave negative results in all tests.

Of 320 samples from patients with a history of bloody diarrhoea, $28(8 \cdot 8 \%)$ were ELISA-positive and $23(7.2 \%)$ of these yielded $E$. coli $\mathrm{O} 157$ on SMA. Four ELISA-positive, SMA culture-negative samples yielded SLT-producing $E$. coli belonging to serogroups other than O157. In one case that was ELISA-positive for SLT-II, no SLT-producing $E$. coli was isolated.

In 120 samples from patients with non-bloody diarrhoea, SLT-producing $E$. coli were detected in five samples $(4 \%)$ by ELISA but only 3 samples (2.5\%) yielded $E$. coli $\mathrm{O} 157$ on SMA. In the remaining two cases, $E$. coli $\mathrm{O} 157$ was isolated by colony blot.

\section{ELISA performance}

The mean $\mathrm{A}_{405}$ for the $1.6 \mathrm{ng} / \mathrm{ml}$ standards of SLTI and SLT-II were 0.35 (range $0 \cdot 30-0.49$ ) and 0.27 (range $0 \cdot 23-0 \cdot 35$ ), respectively, with a substrate-con- 
taining well as blank. Typical negative samples had $\mathrm{A}_{405}$ in the SLT-I and SLT-II ELISA of $0-0.12$ and $0-0.09$, respectively. Samples that contained SLT-I typically had $\mathrm{A}_{405}$ of $0 \cdot 5->2$ and for SLT-II-positive samples the range of $A_{405}$ values was $0.4->2$. Over $80 \%$ of samples containing SLT-producing E. coli gave $\mathrm{A}_{405}$ values $>2$.

If SLT-producing E. coli isolation on either SMA or by colony blot was regarded as the definitive test, the ELISA had a sensitivity and specificity of $100 \%$ and $99.7 \%$, respectively. Positive and negative predictive values were $98 \cdot 1 \%$ and $100 \%$.

\section{Discussion}

The purpose of this study was to compare the efficacy of SLT ELISA on supernates and cell lysates after culture of faeces in broth containing mitomycin $\mathrm{C}$ with culture on SMA in the detection of infections caused by SLT-producing E. coli. The ELISA method proved superior to SMA culture and detected 11 $(20 \%)$ of cases of infection with SLT-producing E. coli that were not detected by culture on SMA. Low numbers of $E$. coli $\mathrm{O} 157$ were detected subsequently in seven of these samples and non-O157 SLT-producing $E$. coli were isolated from four samples. It is not surprising that the SMA method failed to detect infection caused by non-O157 serogroups as these four isolates fermented sorbitol and were indistinguishable from normal flora $E$. coli on SMA. The ability of the ELISA to detect SLT-producing $E$. coli of serogroups other than 0157 is a distinct advantage over SMA culture.

The apparent incidence of SLT-producing $E$. coli infection in this study is high ( 53 of 475 cases) but this is not a reflection of the true incidence of this infection. Eleven isolates were from a single outbreak and 36 faecal samples (including eight from the outbreak) were sent for confirmation of E. coli $\mathrm{O} 157$ isolation.

Because many laboratories are unable to examine samples for SLT-producing $E$. coli of serogroups other than $\mathrm{O} 157$, there is little information concerning the incidence of $E$. coli strains other than $\mathrm{O} 157$ in disorders other than HUS, although it is thought to be lower than the incidence of $E$. coli $0157 .^{18,19}$ In this study 439 samples formed a blind prospective evaluation of the ELISA method. Seventeen of the samples yielded SLT-producing $E$. coli, of which 13 were E. coli $\mathrm{O} 157$ and four $(24 \%)$ were non-O157 SLTproducing E. coli. All four non-O157 isolates were from cases of bloody diarrhoea. The high incidence of serogroups other than $\mathrm{O} 157$ as a cause of bloody diarrhoea may reflect the use of a sensitive diagnostic test. By means of this method we can now ascertain the true incidence of non-O157 SLT-producing E. coli as a cause of diarrhoea.

There was one apparent false positive reaction in the 475 samples examined by the ELISA method. The culture supernate of this sample contained low $(12.5 \mathrm{ng} / \mathrm{ml})$ quantities of SLT-II, but SLT-producing $E$. coli were not isolated from this sample by SMA, colony blot or colony sweeps. The reason for this is not clear but may be due to infection caused by an SLT-producing $E$. coli present in very low numbers.

The diagnosis of HUS is clinical but the detection of SLT-producing E. coli can confirm the diagnosis and is of particular value in unusual cases. In this study, the ELISA detected three cases of E. coli $\mathrm{O} 157$ infection that were not detected by SMA. The low isolation rate of SLT-producing $E$. coli in HUS cases in this study (11 of 25) is similar to that found in other studies and is likely to be due to loss of pathogens as a result of delays in receiving samples. This was illustrated in one case when three samples were received from one child with HUS and were consistently negative by ELISA, SMA culture and colony blot. The samples were 1week-old before they were examined in this study and E. coli $\mathrm{O} 157$ had been isolated previously on SMA at the referring hospital. Serological techniques have been employed successfully in diagnosing some infections that are culture negative..$^{20}$

The main disadvantage of the ELISA method is that, although it detects the presence of toxin-producing organisms in a broth culture, the organism is not available for further characterisation by serotyping, phage typing or toxin studies. If $E$. coli $\mathrm{O} 157$ is present in large numbers it will be detected on SMA. However, if low numbers of E. coli $\mathrm{O} 157$ or a nonO157 SLT-producing E. coli are present in the faeces, the ELISA will be positive but no pathogens will be detected on SMA. In such cases we used a colony blot technique and tested colony sweeps to obtain pure cultures of toxin-producing strains for further characterisation. Alternatively, mixed cultures that are ELISA positive could be examined by gene probe techniques.

The culture of faecal samples in broth containing mitomycin C followed by ELISA for SLTs is more sensitive than culture on SMA alone, detects infections in which low numbers of organisms are present and those caused by non-O157 serogroups. We propose that this technique, used routinely in conjunction with culture on SMA, is an economical method of providing a rapid diagnosis of most human gastrointestinal infection caused by SLT-producing E. coli.

We thank the Division of Enteric Pathogens, Central Public Health Laboratory, Colindale Avenue, London for serotyping and toxin confirmation tests. D.W.K.A. was supported by a Health Sciences for the Tropics Partnership in Research and Training Grant from the Rockefeller Foundation, New York, USA. 


\section{References}

1. Kleanthous H, Smith HR, Scotland SM et al. Haemolytic uraemic syndromes in the British Isles, 1985-8: association with Verocytotoxin producing Escherichia coli. Part 2: microbiological aspects. Arch Dis Childhood 1990; 65: $722-727$.

2. Riley LW. The epidemiologic, clinical and microbiologic features of hemorrhagic colitis. Annu Rev Microbiol 1987; 41: 383-407.

3. Karmali MA, Petric M, Lim C, Fleming PC, Arbus GS, Lior $\mathrm{H}$. The association between idiopathic hemolytic uremic syndrome and infection by verotoxin-production Escherichia coli. J Infect Dis $1985 ; 151$ : 775-782.

4. Karmali MA. Infection by verocytotoxin-producing Escherichia coli. Clin Microbiol Rev 1989; 2: 15-38.

5. PHLS Escherichia coli $\mathrm{O} 157$ Working Group. Laboratory diagnosis of infection caused by vero-cytotoxin-producing Escherichia coli of serogroup O157. PHLS Microbiology Digest 1991; 7: 94-95.

6. Tarr PI, Neill MA, Clausen CR, Watkins SL, Christie DL, Hickman RO. Escherichia coli $\mathrm{O} 157: \mathrm{H} 7$ and the hemolytic uremic syndrome: importance of early cultures in establishing the etiology. $J$ Infect Dis $1990 ; 162$ : 553-556.

7. Ritchie M, Partington S, Jessop J, Kelly MT. Comparison of a direct fecal shiga-like toxin assay and sorbitol-MacConkey agar culture for laboratory diagnosis of enterohemorrhagic Escherichia coli infection. J Clin Microbiol 1992; 30: 461-464.

8. Newland JW, Neill RJ. DNA probes for Shiga-like toxins I and II and for toxin-converting bacteriophages. $J$ Clin Microbiol 1988; 26: 1292-1297.

9. Bettleheim KA, Brown JE, Lolekha S, Echeverria P. Serotypes of Escherichia coli that hybridized with DNA probes for genes encoding Shiga-like toxin I, Shiga-like toxin II, and serogroup 0157 enterohemorrhagic $E$. coli fimbriae isolated from adults with diarrhea in Thailand. $J$ Clin Microbiol 1990; 28: 293-295.

10. Scotland SM, Rowe B, Smith HR, Willshaw GA, Gross RJ. Verocytotoxin-producing strains of Escherichia coli from children with haemolytic uraemic syndrome and their detection by specific DNA probes. $J$ Med Microbiol 1988; 25: $237-243$.
11. Thomas A, Smith HR, Willshaw GA, Rowe B. Non-radioactively labelled polynucleotide and oligonucleotide DNA probes, for selectively detecting Escherichia coli strains producing Vero cytotoxins. VT1, VT2 and VT2 variant. Mol Cell Probes 1991; 5: 129-135.

12. Pollard DR, Johnson WM, Lior H, Tyler SD, Rozee KR. Rapid and specific detection of verotoxin genes in Escherichia coli by the polymerase chain reaction. J Clin Microbiol 1990; 28: 540-545.

13. Acheson DWK, Keusch GT, Lightowlers M, Donohue-Rolfe A. Enzyme-linked immunosorbent assay for Shiga toxin and Shiga-like toxin II using $P_{1}$ glycoprotein from hydatid cysts. $J$ Infect Dis 1990; 161: 134-137.

14. Downes FP, Green JH, Greene K, Strockbine N, Wells JG, Wachsmuth IK. Development and evaluation of enzymelinked immunosorbent assays for the detection of Shigalike toxin I and Shiga-like toxin II. J Clin Microbiol 1989; 27: 1292-1297.

15. Law D, Ganguli LA, Donohue-Rolfe A, Acheson DWK. Detection by ELISA of low numbers of Shiga-like toxinproducing Escherichia coli in mixed cultures after growth in the presence of mitomycin C. J Med Microbiol 1992; 36: 198-202.

16. Head SC, Petric M, Richardson S, Roscoe M, Karmali MA. Purification and characterization of verocytotoxin 2. FEMS Microbiol Lett 1988; 51: 211-216.

17. Donohue-Rolfe A, Acheson DWK, Kane AV, Keusch GT. Purification of Shiga toxin and Shiga-like toxins I and II by receptor analog affinity chromatography with immobilized $P_{1}$ glycoprotein and the production of cross-reactive monoclonal antibodies. Infect Immun 1989; 57: 3888-3893.

18. Pai $\mathrm{CH}$, Ahmed N, Lior H, Johnson WM, Sims HV, Woods DE. Epidemiology of sporadic diarrhea due to verocytotoxin-producing Escherichia coli: a two-year prospective study. J Infect Dis 1988; 157: 1054-1057.

19. Edelman R, Karmali MA, Fleming PA. Summary of the International Symposium and Workshop on Infections due to Verocytotoxin (Shiga-like toxin)-producing Escherichia coli. J Infect Dis 1988; 157: 1102-1104.

20. Chart H, Scotland SM, Rowe B. Serum antibodies to Escherichia coli serotype 0157:H7 in patients with hemolytic uremic syndrome. J Clin Microbiol 1989; 27: 285-290. 